\title{
Equilibrium States of Liquid, Solid, and Vapor and the Configurations for Copper, Tungsten, and Pores in Liquid-Phase Sintering
}

\begin{abstract}
JONATHAN FIKES, SEONG JIN PARK, and RANDALL M. GERMAN
The equilibrium state of the liquid-solid structure during liquid-phase sintering (LPS) is pondered with respect to minimum energy geometries. Besides the solid-liquid ratio, several interfacial energies determine the most stable geometric configuration. In this study, we rely on the attributes of the copper or nickel as the liquid, tungsten as the solid, and vapor to solve for terminal configurations that include liquid pools inside the solid grains. Surface evolution is enabled using a stepwise computer program ${ }^{[1]}$ to rearrange and reshape small grain clusters reflective of LPS based on a preset combination of wetting and dihedral angles. The findings show how different interfacial energies, as a result of oxidation or impurity segregation, play a role in determining the final geometry. The specific concern is identification of situations in which a liquid is stable inside the solid, as observed in some LPS materials.
\end{abstract}

DOI: $10.1007 / \mathrm{s} 11663-010-9460-7$

(C) The Minerals, Metals \& Materials Society and ASM International 2010

\section{INTRODUCTION}

LIQUID-PHASE sintering (LPS) is applied to the consolidation of mixed powder compacts to produce high-performance composite materials. During heating, a liquid forms, spreads, bonds, and usually densifies the solid grains. ${ }^{[2]}$ In most cases, the liquid forms at temperatures far below the melting range for the solid. Once the liquid flows, the solid grains rearrange and pore space is filled with a more efficient grain arrangement accompanying liquid flow and grain shape accommodation. As a consequence, the starting powder geometry (size, shape, and spacing) transforms during LPS to give a microstructure that usually involves a liquid laced along the grain boundaries of the solid grains.

Beere ${ }^{[3]}$ Wray, ${ }^{[4]}$ and Kipphut et al. ${ }^{[5]}$ solved for some equilibrium geometries in which the volume fraction of the solid and the dihedral angle were used to determine the grain configuration. These are two-phase solutions in which the starting conditions correspond to three phases, solid-liquid-vapor (pore), but this structure is ignored in the solid-liquid solutions just mentioned. ${ }^{[3-5]}$ Consequently, some grain geometries develop outside those predicted, such as pores located inside liquid pockets that, in turn, are located inside solid grains, such as shown by Liu et al. ${ }^{[6]}$ Other examples are observed in

JONATHAN FIKES, Undergraduate Student, is with the Mechanical Engineering Department, Mississippi State University, Starkville, MS 39759. SEONG JIN PARK, Associate Professor, is with the Department of Mechanical Engineering, Pohang University of Science and Technology, Pohang 790-784, South Korea. Contact e-mail: sjpark87@postech.ac.kr RANDALL M. GERMAN, Associate Dean, is with the College of Engineering, San Diego State University, San Diego, CA 92101.

Manuscript submitted May 14, 2009.

Article published online December 9, 2010. tungsten heavy alloys, cermets, and composites in which liquid pools exist inside the solid grains. Figure 1 is a cross-section micrograph of a LPS tungsten heavy alloy in which solidified liquid pockets are evident in several single crystal tungsten grains. Trapped liquid pockets inside solid grains are evident in several LPS systems. Besides W-Ni, titanium carbide cermets with a ferrous matrix show this attribute as well as mixed carbides consisting of titanium-tungsten carbo nitrides in a cobalt matrix, such as (Ti,W)(C,N)-Co, ( TiC-WC-MoC)$(\mathrm{Ni}, \mathrm{Co}), \mathrm{Fe}-\mathrm{Cu}$, and Mo-Ni. ${ }^{[2,7-11]}$ Because systems are different in many regards, but the formation of liquid pockets inside the solid grains seems to be a reflection of grain growth and the trapping of liquid by coalescence rather than a system specific factor.

These inside-out variants of liquid inside the solid grain are not included in the equilibrium geometry treatments mentioned. Thus, including the initial three phases (solid, liquid, and vapor) in solving for the lowest energy provides insight as to other metastable or minimum energy solutions, including situations in which pores or liquid pools are stable inside the solid grains. The final equilibrium depends on the combination of materials, relative proportion of phases, and interfacial energies. The systems used here are tungsten-copper and tungsten-nickel. These alloys, generally termed heavy alloys, have practical applications in welding, electrical contacts, heat sinks, radiation shielding, vibrator weights, self-winding watches, cellular telephone vibrators, aircraft wing weights, and computer disk drives. Tungsten-copper, tungsten-nickel, and related alloys are used in LPS research because of the controlled solubility of the phases. For example, W-Cu is essentially insoluble, whereas $\mathrm{W}-\mathrm{Ni}$ has high intersolubility and $\mathrm{Ni}-\mathrm{Cu}$ is isomorphous, allowing observation of the rearrangement and densification with a range of solvation events during heating. ${ }^{[12,13]}$ 


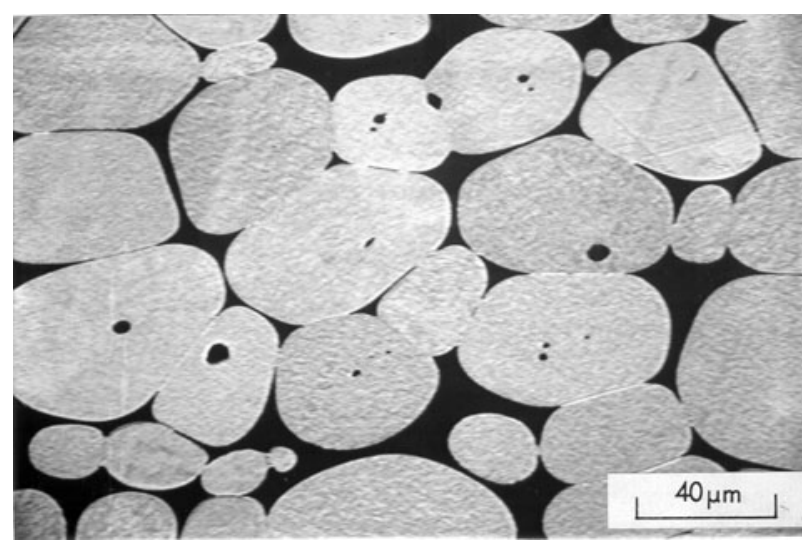

Fig. 1-Cross section through a LPS tungsten heavy alloy (95W$3.5 \mathrm{Ni}-1.5 \mathrm{Fe}$ ) showing pools of solidified liquid (dark) inside solid tungsten grains (light).

We examine the tungsten-copper and tungsten-nickel systems as well as the evolution of the three phase configurations based on various assumed interfacial parameters. Endpoint configuration calculations are performed, whereas Surface Evolver ${ }^{[1]}$ is used to track the evolution of the low-energy configurations. Using changes in the input parameters, configurations are evolved to determine the final spatial arrangement. We include three phases-liquid copper or nickel, solid tungsten, and vapor. Furthermore, we allow for some variability in interfacial energies. Changes in interfacial energies reflect differences in impurity segregation and crystal misorientation. Huppmann and Reigger ${ }^{[12]}$ demonstrated this effect in W-Cu during their examination of wetting effects on rearrangement in the early stage of LPS. Another demonstration is observed when trace transition metal additives result in significant densification shifts. For example, Barta ${ }^{[14]}$ shows for LPS W-1.5Ag-3.5Cu alloys the addition of $0.1 \mathrm{wt}$ pct nickel changed the $1473 \mathrm{~K}\left(1200{ }^{\circ} \mathrm{C}\right)$ sintered density from 12.3 to $17.5 \mathrm{~g} / \mathrm{cm}^{3}$.

The current study demonstrates how the interfacial energies and the liquid content produce different grain configurations. The configurations reported here start with ratios of grains ranging from one-to-one (e.g., $1 \mathrm{Cu}$ grain surrounded by $1 \mathrm{~W}$ grain, $1 \mathrm{~W}$ grain surrounded by $1 \mathrm{Cu}$ grain, 1 pore surrounded by $1 \mathrm{Cu}$ grain, or 1 pore surrounded $1 \mathrm{~W}$ grain) to one-to-four (e.g., $1 \mathrm{Cu}$ grain surrounded by $4 \mathrm{~W}$ grains, $1 \mathrm{~W}$ grain surrounded by $4 \mathrm{Cu}$ grains, 1 pore surrounded by $4 \mathrm{Cu}$ grains, or 1 pore surrounded $4 \mathrm{~W}$ grains) to one-to-six (e.g., $1 \mathrm{Cu}$ grain surrounded by $6 \mathrm{~W}$ grains, $1 \mathrm{~W}$ grain surrounded by $6 \mathrm{Cu}$ grains, 1 pore surrounded by $6 \mathrm{Cu}$ grains, or 1 pore surrounded $6 \mathrm{~W}$ grains). We use Surface Evolver ${ }^{[1]}$ to calculate the total interfacial energy for determining which configuration among the previous configurations is the easiest to form in the equilibrium state.

\section{STABILITY OF LIQUID INSIDE SOLID GRAINS}

From a geometric view, two terminal situations are considered. One is a spherical liquid droplet inside a

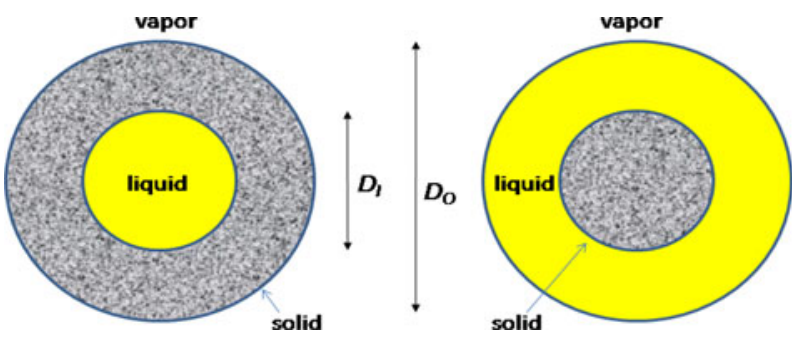

Fig. 2-Liquid on the inside and on the outside of the solid grains as well as a definition of the two diameters and the three phases.

spherical solid grain in which the grain is surrounded by vapor. The second is a spherical coating of liquid in contact with the vapor on a spherical grain, sketched in Figure 2. Both cases assume isotropic surface energies.

The problem involves three interfacial energies $\gamma_{\mathrm{SL}}$ (solid-liquid), $\gamma_{\mathrm{SV}}$ (solid-vapor), and $\gamma_{\mathrm{LV}}$ (liquid-vapor). These three energies are related through the contact angle $\theta$ as illustrated in Figure 3. These three interfacial energies are related as follows ${ }^{[15]}$.

$$
\gamma_{\mathrm{SV}}=\gamma_{\mathrm{SL}}+\gamma_{\mathrm{LV}} \cos \theta
$$

Let $f$ equal the liquid fraction at full density, where $V_{\mathrm{L}}$ is the liquid volume and $V_{\mathrm{S}}$ is the solid volume, so the liquid fraction $f$ is given by the following equation:

$$
f=\frac{V_{\mathrm{L}}}{V_{\mathrm{L}}+V_{\mathrm{S}}}
$$

For simplification, although porosity is not preserved, we still can set the total liquid plus the solid volume to unity, so $1=V_{\mathrm{L}}+V_{\mathrm{S}}$, as a means to simplify the calculation of the outer diameter $D_{\mathrm{O}}$ as follows:

$$
D_{\mathrm{O}}=\left(\frac{6}{\pi}\right)^{1 / 3}
$$

Likewise, the inner diameter $D_{\mathrm{I}}$ is given by the following related expression:

$$
D_{\mathrm{I}}=\left(\frac{6 f}{\pi}\right)^{1 / 3}
$$

For isotropic materials in which no change occurs in surface energy with orientation, the corresponding configurational energy $E_{I}$, reflected by the left side of Figure 2 (liquid on the inside), is expressed as follows by the sum of interfacial energies times the respective surface areas:

$$
E_{\mathrm{I}}=\pi\left(D_{\mathrm{O}}^{2} \gamma_{\mathrm{SV}}+D_{\mathrm{I}}^{2} \gamma_{\mathrm{LV}}\right)
$$

Substituting Eqs. [3] and [4] into Eq. [5] yields the following:

$$
E_{\mathrm{I}}=\pi\left(\frac{\pi}{6}\right)^{2 / 3}\left(\gamma_{\mathrm{SV}}+f^{2 / 3} \gamma_{\mathrm{LV}}\right)
$$

By similar logic, the inverse problem shown on the right side of Figure 2, with liquid on the outside gives 


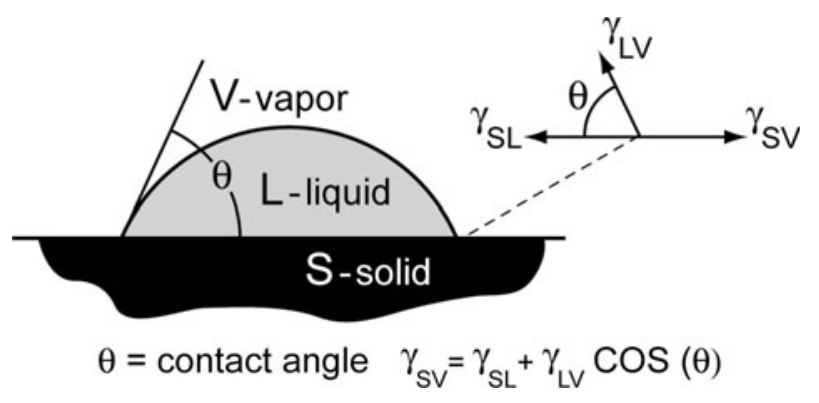

Fig. 3-The solid-liquid-vapor equilibrium in the horizontal direction gives a definition of the contact angle.

the configurational energy for outside liquid as follows:

$$
E_{\mathrm{O}}=\pi\left(\frac{\pi}{6}\right)^{2 / 3}\left[\gamma_{\mathrm{LV}}+(1-f)^{2 / 3} \gamma_{\mathrm{LS}}\right]
$$

Many terms cancel when solving for the case in which the lower energy is for liquid on the inside gives the following simplifying inequality:

$$
\gamma_{\mathrm{SV}} \leq \gamma_{\mathrm{LV}}+\gamma_{\mathrm{SL}} F
$$

where the new term $F$ is a direct function of the liquid volume fraction, which is given as follows:

$$
F=(1-f)^{2 / 3}-f^{2 / 3}
$$

Note the term $F$ ranges from unity, with no liquid, to zero at $50 \mathrm{vol}$ pet liquid. The term $F$ is negative for less than 50 vol pet liquid.

To solve for the case of liquid on the inside, rearranging the terms gives the following form:

$$
\frac{\gamma_{\mathrm{SV}}}{\gamma_{\mathrm{SL}}} \leq \frac{\gamma_{\mathrm{LV}}}{\gamma_{\mathrm{SL}}}+F
$$

or using the definition of the contact angle from Eq. [1] allows the following expression:

$$
\gamma_{\mathrm{SL}}(1-F) \leq \gamma_{\mathrm{LV}}(1-\cos \theta)
$$

Under which conditions will these inequalities in Eqs. [8] or [11] be satisfied? Because $F$ tracks to unity as the liquid quantity decreases, small liquid contents or isolated small liquid regions favor the formation of liquid pools. A cluster of solid grains surrounding a small liquid pocket enables the grains to coalesce while the liquid forms a spherical pool inside the coalesced structure. Findings on grain growth during LPS shows strong evidence of coalescence, ${ }^{[16]}$ so this is not an isolated situation. Thus, one explanation of the isolated liquid pockets evident in Figure 1 comes from grain coalescence around a small isolated liquid pool. This does not imply an overall low liquid content, only that inhomogeneous liquid distribution exists such that coalescing solid grains capture the liquid. Subsequent densification then would produce a structure that might have a high overall liquid content but with pools of liquid inside the coalesced solid grains.

Tests of this model are possible using typical properties for a tungsten heavy alloy in which the tungsten

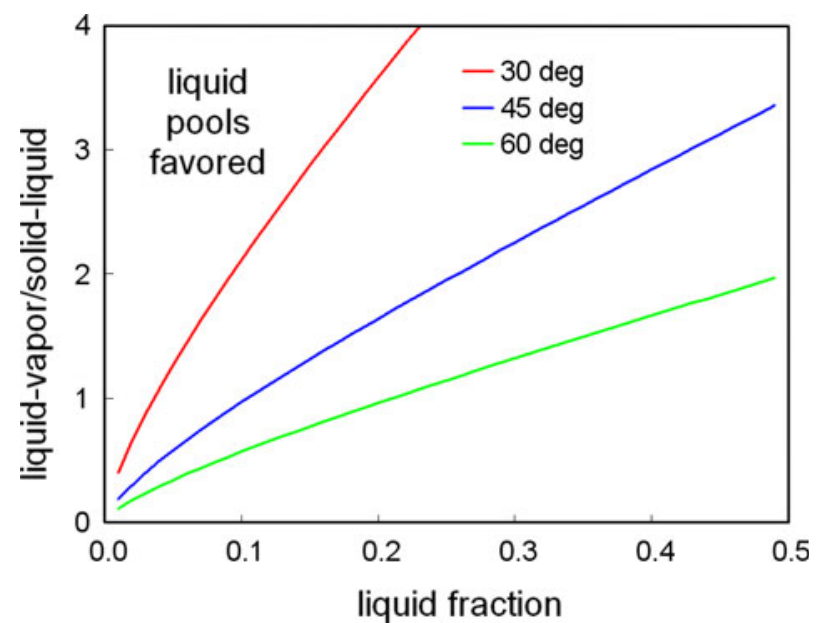

Fig. 4-Plots of the liquid-vapor to solid-liquid interfacial energy ratio $v s$ the liquid volume fraction for three contact angles; liquid pools are favored for conditions above each line.

solid-vapor interfacial energy is assumed to be $2.8 \mathrm{~J} / \mathrm{m}^{2}$ and the respective liquid vapor interfacial energy for copper and nickel are 1.2 and $1.8 \mathrm{~J} / \mathrm{m}^{2}$, respectively. ${ }^{[17,18]}$ In the $\mathrm{W}-\mathrm{Ni}$ system, the contact angle changes over time as solid dissolves into the liquid. Assuming an intermediate contact angle of $40 \mathrm{deg}$ between liquid $\mathrm{Ni}$ and solid $\mathrm{W}$ gives a solid-liquid interfacial energy of $1.42 \mathrm{~J} / \mathrm{m}^{2}$. Although tungsten is soluble in nickel at high temperatures, this solubility is ignored here. For this case, liquid pool formation is predicted up to about $10 \mathrm{vol}$ pct liquid. The microstructure shown in Figure 1 corresponds to about 10 vol pct liquid, so the observation helps confirm the calculation.

In LPS the solid-liquid interfacial energy is generally smaller than the liquid-vapor energy. For example, assume $15 \mathrm{vol}$ pct liquid and a contact angle of $30 \mathrm{deg}$. For this case $F=0.62$, so $1-F=0.38, \cos \theta=0.87$, so $1-\cos \theta=0.13$. The parameter that determines whether liquid is stable on the inside is the ratio of liquid-vapor to solid-liquid interfacial energies $\left(\gamma_{\mathrm{LV}}\right)$ $\gamma_{\mathrm{SL}}$ ). For this case, with $15 \mathrm{vol}$ pct liquid, the ratio of these two interface energies needs to be greater than 3 . The combinations favoring liquid pools are plotted in Figure 4 for three contact angles $(\theta=30 \mathrm{deg}, 45 \mathrm{deg}$, or $60 \mathrm{deg}) v s$ the liquid fraction $f$. The ratios of $\left(\gamma_{\mathrm{LV}} / \gamma_{\mathrm{SL}}\right)$ are shown, indicating that a high liquid content is not favorable for the formation of a liquid pool inside the solid.

These results show that, as the liquid fraction increases, the tendency for liquid pooling decreases. A secondary correction becomes important for small liquid pools when the curvature is small because the liquid pool energy will increase as a result of capillary compression. Note that a similar calculation can be constructed for the determination of conditions when a vapor pool or a pore would be stable inside the liquid or solid grain; however, in this case, volume is not conserved because pore space is compressible. The standard assumption is that the pore pressure varies with the inverse of the pore diameter, so the calculation 
of a minimum energy configuration has several added terms. ${ }^{[2]}$

\section{SIMULATION BY SURFACE EVOLVER}

Confirmation calculations further isolated the conditions for liquid pocket formation. Surface Evolver is a computer program designed to study how interfacial energy, composition, and phase content govern the stability of different material combinations. ${ }^{[1]}$ The energies in a system include contributions from interfaces, curvature, gravity, and other user-defined sources. The surfaces are defined by an input data file that includes interfacial energies. The initial geometry consists of sets of defined triangular finite elements or facets. ${ }^{[18]}$ Assuming isotropic behavior, the energy is proportional to its area and the terminal minimal energy is achieved by evolving a geometric configuration using a gradient descent method. A more refined mesh is used on each calculation cycle to improve the surface area accuracy, but the refined mesh results in an increase in computational time.

Each simulation starts from a data file that identifies the initial geometric shape and energies. With each calculation cycle, a shape evolves toward a minimized energy configuration for the system. In some cases, the final solution could be a metastable configuration because Surface Evolver tracks toward a local minimum.

Input parameters include the material properties, initial geometry, and simulation parameters. The material properties consist of density, volume, and interfacial energy for each element corresponding to its composition. The simulation parameters consist of the number of iterations, number of mesh refinements, and types of gradient descents (remeshing) used to evolve the surface to a minimal energy condition.

\section{A. Material Properties}

For the tungsten-copper system, the material properties include the densities of tungsten and copper, and the interfacial energies corresponding to the copper-free surface, tungsten-free surface, and the combinations of $\mathrm{Cu}-\mathrm{W}, \mathrm{Cu}-\mathrm{Cu}$, and $\mathrm{W}-\mathrm{W}$. For the simulation, the density and solid-vapor interfacial energy were assumed at $19.3 \mathrm{~g} / \mathrm{cm}^{3}$ (tungsten) and $9.0 \mathrm{~g} / \mathrm{cm}^{3}$ (copper), 2.8 $\mathrm{J} / \mathrm{m}^{2}$ (tungsten), and $1.2 \mathrm{~J} / \mathrm{m}^{2}$ (copper), where the interfacial energy corresponds to vacuum above the copper melting temperature. ${ }^{[16]}$ The combinations used in this study are given in Table I.

The contact angle between liquid copper and solid tungsten was adjusted from $20 \mathrm{deg}$ to $60 \mathrm{deg}$. As mentioned earlier, such changes are possible in the $\mathrm{W}-\mathrm{Cu}$ system based on powder oxidation. ${ }^{[12]}$ In addition, similar simulations were conducted for $\mathrm{W}-\mathrm{Ni}$ using $1.8 \mathrm{~J} / \mathrm{m}^{2}$ as the surface energy for liquid nickel. The three-phase equilibrium is reflected by the contact angle based on Figure 3. In addition, a solid-solid interfacial energy is used to reflect the grain boundary energy. Angles of $5 \mathrm{deg}$ and $20 \mathrm{deg}$ were assumed for the grain
Table I. Material Properties used in this Study*

\begin{tabular}{llcc}
\hline Element & & & Density $\left(\mathrm{g} / \mathrm{cm}^{3}\right)$ \\
\hline $\mathrm{Cu}$ & & 9.0 \\
$\mathrm{Ni}$ & & 9.0 \\
$\mathrm{~W}$ & & & 19.3 \\
\hline & & Contact Angle & Interfacial \\
Element 1 & Element 2 & (Degree) & Energy $\left(\mathrm{J} / \mathrm{m}^{2}\right)$ \\
\hline $\mathrm{Ni}$ & Vapor & - & 1.80 \\
$\mathrm{Cu}$ & Vapor & - & 1.24 \\
& $\mathrm{Cu}$ & 5 & 0.005 \\
& & 20 & 0.08 \\
& $\mathrm{~W}$ & 20 & 1.64 \\
$\mathrm{~W}$ & & 60 & 2.18 \\
& $\mathrm{Vapor}$ & - & 2.80 \\
& $\mathrm{~W}$ & 5 & 0.01 \\
& & 20 & 0.17 \\
\hline
\end{tabular}

*The interfacial energy between the same elements corresponds to the average grain boundary energy.

boundary dihedral angles in $\mathrm{Cu}-\mathrm{Cu}$ and $\mathrm{W}-\mathrm{W}$. The corresponding interfacial energy is calculated based on Eq. [1]. The dihedral angle $\varphi$ relates the grain boundary energy $\gamma_{\mathrm{SS}}$ to the interfacial energy by the standard relation $2 \gamma \cos (\varphi / 2)$, where $\gamma$ would be the opposing solid-liquid or solid-vapor interfacial energy (depending on whether the grain boundary emerges into liquid or vapor).

\section{B. Initial Geometrical Configuration}

The initial geometrical configuration of an element is modeled, using vertices, edges, faces, and bodies. For convenience, a fixed total initial volume for the configuration was set to unity or $1.00 \mathrm{~cm}^{3}$. Four initial configurations were modeled, as shown in Figure 5. Each configuration is explained in the following list:

(a) The first configuration is a cube with a single element (Figure 5(a)).

(b) The second configuration is a cube with the one-toone (1-1) configuration (Figure 5(b)) consisting of two elements. This configuration corresponds to the following four cases: (1) $1 \mathrm{Cu}$ grain surrounded by $1 \mathrm{~W}$ grain, (2) $1 \mathrm{~W}$ grain surrounded by $1 \mathrm{Cu}$ grain, (3) 1 pore surrounded by $1 \mathrm{Cu}$ grain, and (4) 1 pore surrounded $1 \mathrm{~W}$ grain. Red corresponds to the inside feature (copper, tungsten, or pore).

(c) The third configuration is a pyramid for the one-tofour (1-4) configuration (Figure 5(c)) with two elements. The outside element for the 1-4 configuration has four outside elements. This configuration corresponds to the following four cases: (1) $1 \mathrm{Cu}$ grain surrounded by $4 \mathrm{~W}$ grains, (2) $1 \mathrm{~W}$ grain surrounded by $4 \mathrm{Cu}$ grains, (3) 1 pore surrounded by $4 \mathrm{Cu}$ grains, or (4) 1 pore surrounded $4 \mathrm{~W}$ grains. Red corresponds to one inside grain (cupper, tungsten, or pore), while to aid in visualization, and blue corresponds to two outside grains, from the four outside grains. 


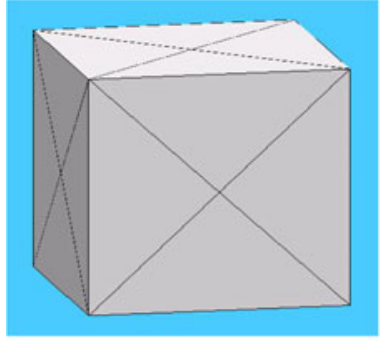

(a)

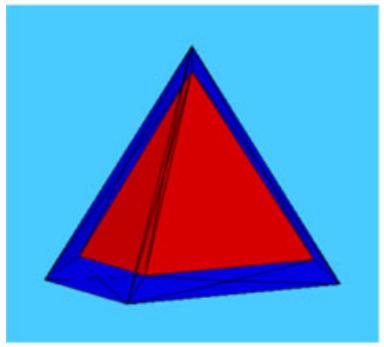

(c)

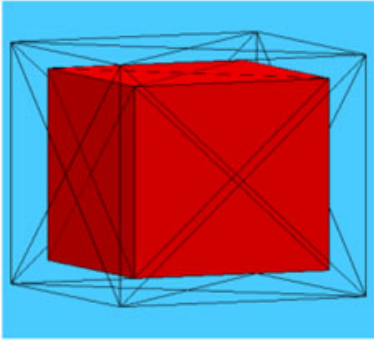

(b)

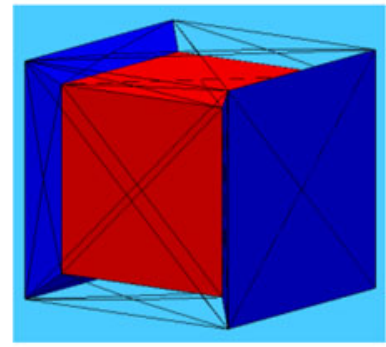

(d)

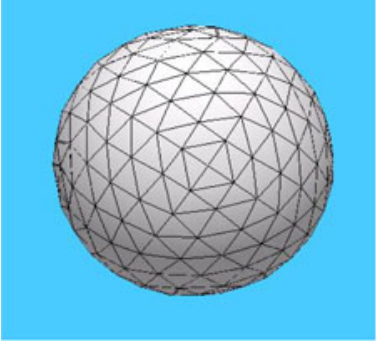

(a)

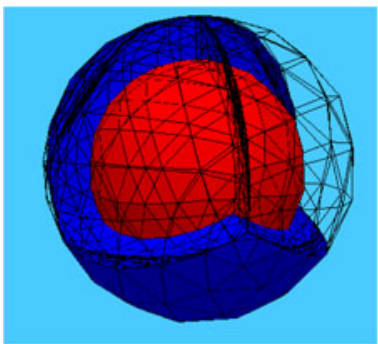

(c)

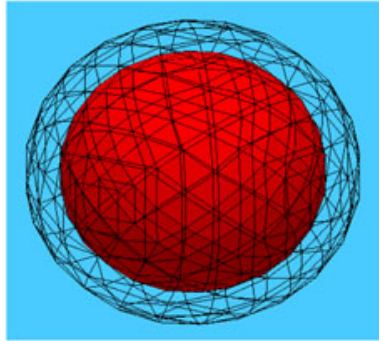

(b)

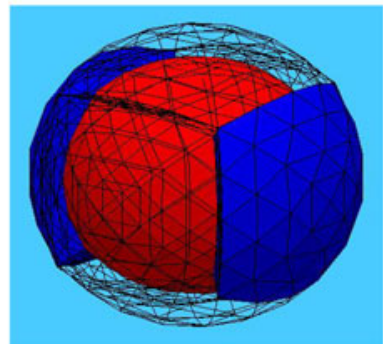

(d)
Fig. 5-Representations of some initial configurations used in this analysis: (a) one element, (b) 1-1 configuration (c) 1-4 configuration, and $(d)$ 1-6 configuration.

(d) The last configuration is a cube for the one-to-six (1-6) configuration (Figure 5(d)) for two elements. The outside element for the 1-6 configuration has six grains. This configuration corresponds to the following four cases: (1) $1 \mathrm{Cu}$ grain surrounded by $6 \mathrm{~W}$ grains, (2) $1 \mathrm{~W}$ grain surrounded by $6 \mathrm{Cu}$ grains, (3) 1 pore surrounded by $6 \mathrm{Cu}$ grains, or (4) 1 pore surrounded $6 \mathrm{~W}$ grains. Red corresponds to one inside grain (cupper, tungsten, or pore), whereas blue corresponds to two outside grains out of six outside grains for visualization.

\section{Simulation Parameters}

The simulation parameters consisted of the number of iterations, number of mesh refinements, and types of gradient descent (remeshing) used to evolve the surface to a minimal or metastable interfacial energy. Internal pressure and capillarity from curvatures of small features are ignored. Each of the iterations used in the evolution of a surface reduces the energy of the system by moving the vertices in the direction of its velocity. The velocity of the vertices is calculated by Surface Evolver, with a goal of shrinking the surface to minimal energy by assuming energy and surface area are related. In this problem, interfacial energy is proportional to the interfacial area; therefore, evolving to a minimal area provides a means to calculate the minimal energy of the system.

After iterating to a minimal area, it is necessary to refine the surface. Refinement helps minimize the area and energy by subdividing each facet into smaller similar facets. Surface Evolver achieves this by creating new vertices at the midpoint of the edges of a facet. The new vertices are moved in the direction of the surface velocity
Fig. 6-Representations of the final configurations used in this analysis with a contact angle of 20 deg between $\mathrm{Cu}$ and $\mathrm{W}$ and $5 \mathrm{deg}$ between $\mathrm{W}$ and $\mathrm{W} ;(a)$ one element $(\mathrm{W}),(b) 1-1$ configuration $(1 \mathrm{Cu}$ grain surrounded by $1 \mathrm{~W}$ grain), (c) $1-4$ configuration ( $1 \mathrm{Cu}$ grain surrounded by $4 \mathrm{~W}$ grains), and (d) 1-6 configuration (1 $\mathrm{Cu}$ grain surrounded by $6 \mathrm{~W}$ grains).

vector during the next iteration, allowing more of the surface to move to the minimal area. Surface evolver typically uses a gradient descent method in evolving the surface. In this analysis, we found that it is sometimes beneficial to use a conjugate gradient because it is numerically suitable to matrix solutions. In this study, the conjugate gradient makes adjustments to the gradient descent by using the history of minimizing the surface (i.e., the history vector). The simulation parameters were the same for all configurations.

\section{RESULTS AND DISCUSSION}

Figure 6 shows the final shapes expected after sintering for a long time. Each configuration is explained in

(a) The result shown in Figure 6(a) is from the first configuration of W (Figure 5(a)). The final shape becomes a perfect sphere, as expected. The same result is obtained for $\mathrm{Cu}$.

(b) The result shown in Figure 6(b) is from the second configuration with $1 \mathrm{Cu}$ grain surrounded by $1 \mathrm{~W}$ grain (Figure 5(b)). The final shape becomes concentric spheres, as expected. Red shows the final shape of an inside pool of $\mathrm{Cu}$. The same result is obtained in the other cases including $1 \mathrm{~W}$ grain surrounded by $1 \mathrm{Cu}$ grain, 1 pore surrounded by 1 $\mathrm{Cu}$ grain, and 1 pore surrounded $1 \mathrm{~W}$ grain.

(c) The result shown in Figure 6(c) is from the third configuration with $1 \mathrm{Cu}$ grain surrounded by $4 \mathrm{~W}$ grains (Figure 5(c)): The final shape is almost the same as in the second case. Blue shows the final the following list: 
shape of the two outside grains, whereas red shows the final shape of the inside $\mathrm{Cu}$ grain. We have the same shapes for all four outside grains. The same result is obtained in the other cases including $1 \mathrm{~W}$ grain surrounded by $4 \mathrm{Cu}$ grains, 1 pore surrounded by $4 \mathrm{Cu}$ grains, and 1 pore surrounded $4 \mathrm{~W}$ grains.

(d) The result shown in Figure 6(d) is from the third configuration with $1 \mathrm{Cu}$ grain surrounded by $4 \mathrm{~W}$ grains (Figure 5(d)). The final shape becomes almost the same as in the second case. Blue shows the final shape of the two outside grain, whereas red shows the final shape of the inside grain of $\mathrm{Cu}$. We have the same shapes for all six outside grains. The same result is obtained in the other cases including $1 \mathrm{~W}$ grain surrounded by $6 \mathrm{Cu}$ grains, 1 pore surrounded by $6 \mathrm{Cu}$ grains, and 1 pore surrounded $6 \mathrm{~W}$ grains.
Because of the assumed isotropic surface energy, the final shapes after sintering for a long time is a sphere, both on the inside and the outside, independent of the initial configuration and combination of elements. Over the range investigated, the grain boundary energy has a negligible effect on the final shapes.

Table II lists the $\mathrm{W}-\mathrm{Cu}$ simulations and the results in terms of the total surface and total interfacial energy. These results correspond to the equilibrium state after a long time of sintering. The results are discussed in the following list for each case:

(a) Result for a single element: The total surface area is $4.85 \mathrm{~cm}^{2}$ for both pure $\mathrm{Cu}$ and pure $\mathrm{W}$, which means that the final shape is a perfect sphere, as shown in Figure 6(a). The geometry is evolved from the initial configuration shown in Figure 5(a). The final surface energies are $0.60 \mathrm{~mJ}$ for $\mathrm{Cu}$ and

Table II. Simulation Design and Results for W-Cu

\begin{tabular}{|c|c|c|c|c|c|c|}
\hline \multicolumn{3}{|c|}{ Configuration } & & & & \\
\hline \multirow{2}{*}{$\begin{array}{l}\text { Inside } \\
\text { Element } 1 \\
\text { (E1) }\end{array}$} & \multicolumn{2}{|c|}{ Outside } & \multicolumn{2}{|c|}{ Contact Angle (Degree) } & \multirow[b]{2}{*}{$\begin{array}{c}\text { Total Surface } \\
\text { Area }\left(\mathrm{cm}^{2}\right)\end{array}$} & \multirow[b]{2}{*}{$\begin{array}{l}\text { Total Interfacial } \\
\text { Energy }(\mathrm{mJ})\end{array}$} \\
\hline & $\begin{array}{l}\text { Element } 2 \\
\text { (E2) }\end{array}$ & $\begin{array}{l}\text { Number of } \\
\text { Grains }\end{array}$ & $\begin{array}{c}\text { E1-E2 } \\
\text { (Contact Angle) }\end{array}$ & $\begin{array}{c}\text { E2-E2 } \\
\text { (Grain Boundary) }\end{array}$ & & \\
\hline $\mathrm{Cu}$ & - & - & - & - & 4.85 & 0.60 \\
\hline W & - & - & - & - & 4.85 & 1.36 \\
\hline \multirow[t]{10}{*}{$\mathrm{Cu}$} & W & 1 & 20 & - & 7.91 & 1.86 \\
\hline & & & 60 & - & 7.91 & 2.03 \\
\hline & & 4 & 20 & 5 & 8.75 & 1.86 \\
\hline & & & & 20 & 8.72 & 1.87 \\
\hline & & & 60 & 5 & 8.75 & 2.03 \\
\hline & & & & 20 & 8.72 & 2.04 \\
\hline & & 6 & 20 & 5 & 8.96 & 1.86 \\
\hline & & & & 20 & 8.94 & 1.88 \\
\hline & & & 60 & 5 & 8.96 & 2.03 \\
\hline & & & & $16^{*}$ & 8.97 & 2.04 \\
\hline \multirow[t]{10}{*}{$\mathrm{W}$} & $\mathrm{Cu}$ & 1 & 20 & - & 7.91 & 1.29 \\
\hline & & & 60 & - & 7.91 & 1.44 \\
\hline & & 4 & 20 & 5 & 8.75 & 1.10 \\
\hline & & & & 20 & 8.70 & 1.11 \\
\hline & & & 60 & 5 & 8.73 & 1.27 \\
\hline & & & & 20 & 8.69 & 1.28 \\
\hline & & 6 & 20 & - & - & - \\
\hline & & & & $30^{*}$ & 8.92 & 1.12 \\
\hline & & & 60 & - & - & - \\
\hline & & & & $30^{*}$ & 8.89 & 1.29 \\
\hline \multirow[t]{5}{*}{ Pore } & $\mathrm{Cu}$ & 1 & - & - & 7.91 & 0.92 \\
\hline & & 4 & - & 5 & 8.75 & 0.98 \\
\hline & & & & 20 & 8.70 & 0.99 \\
\hline & & 6 & - & 5 & 8.96 & 0.98 \\
\hline & & & & 20 & 8.95 & 0.98 \\
\hline \multirow[t]{5}{*}{ Pore } & W & 1 & - & - & 7.91 & 2.08 \\
\hline & & 4 & - & 5 & 8.75 & 2.22 \\
\hline & & & & 20 & 8.72 & 2.23 \\
\hline & & 6 & - & 5 & 8.96 & 2.22 \\
\hline & & & & 20 & 8.96 & 2.22 \\
\hline
\end{tabular}

*Angles denoted with asterisk $(*)$ are special cases occurring only with six grains at a contact angle of 20 deg and 60 deg between the two elements due to numerical instabilities of Surface Evolver. 
$1.36 \mathrm{~mJ}$ for $\mathrm{W}$. These values are the same as directly calculated for $1-\mathrm{cm}^{3}$ volume spheres (1.24$\mathrm{cm}$ diameter) and the appropriate surface energies, verifying the Surface Evolver simulation results.

(b) Result for the $\mathrm{Cu}$ inside: The total surface area increases as the number of $\mathrm{W}$ grains increases, but the total interfacial energy is dominated by the contact angle between $\mathrm{Cu}$ and $\mathrm{W}$. A higher contact angle gives a higher total interfacial energy. The total interfacial energy is not sensitive to the number of $\mathrm{W}$ grains and the grain boundary energy between $\mathrm{W}$ grains. Note that the angle denoted with an asterisk $\left(16^{*}\right)$ is the maximum grain boundary dihedral angle with the contact angle of 60 deg between $\mathrm{Cu}$ and $\mathrm{W}$ because of a numerical instability in Surface Evolver. Figures 6(b) through (d) show the final shapes of these cases with a contact angle of 20 deg between $\mathrm{Cu}$ and $\mathrm{W}$ and 5 deg dihedral angle between $\mathrm{W}$ and $\mathrm{W}$ from the initial configurations of Figures 5(b) through (d), respectively. For one $\mathrm{W}$ grain outside, the total surface areas are $7.91 \mathrm{~cm}^{2}$ for contact angles of $20 \mathrm{deg}$ and $60 \mathrm{deg}$ between $\mathrm{Cu}$ and $\mathrm{W}$, which means two perfect spheres with the same centers. The corresponding final interfacial energy are the same values of $1.86 \mathrm{~mJ}$ for the contact angle of $20 \mathrm{deg}$ between $\mathrm{Cu}$ and $\mathrm{W}$ and $2.03 \mathrm{~mJ}$ for $60 \mathrm{deg}$ as the calculated values based on Section II. So we can verify the simulation result of Surface Evolver.

(c) Result for the $\mathrm{W}$ inside: The total surface area increases as the number of $\mathrm{Cu}$ grains increases.
However, the total interfacial energy is only significantly influenced by the contact angle between $\mathrm{Cu}$ and $\mathrm{W}$. The higher contact angle requires a higher interfacial energy. The interfacial energy is insensitive to the number of $\mathrm{Cu}$ grains and the grain boundary energy between $\mathrm{W}$ grains. Note that the angle denoted with an asterisk $\left(30^{*}\right)$ is the minimum angle for grain boundary energy with the contact angles of $20 \mathrm{deg}$ and 60 deg between $\mathrm{Cu}$ and $\mathrm{W}$ because of a numerical instability in Surface Evolver. In the case of one $\mathrm{Cu}$ grain outside, the total surface areas are $7.91 \mathrm{~cm}^{2}$ for both cases of contact angles of $20 \mathrm{deg}$ and 60 deg between $\mathrm{Cu}$ and $\mathrm{W}$, which means two perfect spheres with the same centers. The corresponding final interfacial energy is $1.29 \mathrm{~mJ}$ for the contact angle of $20 \mathrm{deg}$ between $\mathrm{Cu}$ and $\mathrm{W}$ and $1.44 \mathrm{~mJ}$ for $60 \mathrm{deg}$ as the calculated values based on Section II, and so we can verify the simulation result of Surface Evolver.

(d) Result for the pore inside: The total surface area increases as the number of $\mathrm{Cu}$ or $\mathrm{W}$ grains increases. Again, over the range of study, the interfacial energy is not sensitive to the number of $\mathrm{Cu}$ or $\mathrm{W}$ grains and grain boundary energy between W grains. In the case of one $\mathrm{Cu}$ or $\mathrm{W}$ grain outside, the total surface areas are $7.91 \mathrm{~cm}^{2}$ for both cases of $\mathrm{Cu}$ or $\mathrm{W}$ grain, which means two perfect spheres with the same centers. The corresponding final interfacial energies are $0.92 \mathrm{~mJ}$ for the $\mathrm{Cu}$ grain outside and $2.08 \mathrm{~mJ}$ for the $\mathrm{W}$ grain outside as the calculated values based on Section II, and so

Table III. Design and Simulation Results for W-Ni

\begin{tabular}{|c|c|c|c|c|c|c|}
\hline \multicolumn{4}{|c|}{ Configuration } & \multirow{3}{*}{$\begin{array}{l}\text { Contact Angle } \\
\text { of W-Ni (degree) }\end{array}$} & \multirow{3}{*}{$\begin{array}{c}\text { Total Surface } \\
\text { Area }\left(\mathrm{cm}^{2}\right)\end{array}$} & \multirow{3}{*}{$\begin{array}{c}\text { Total Interfacia } \\
\text { Energy }(\mathrm{mJ})\end{array}$} \\
\hline \multicolumn{2}{|c|}{ Inside } & \multicolumn{2}{|c|}{ Outside } & & & \\
\hline Element 1 & Vol pct & Element 2 & Vol pct & & & \\
\hline \multirow[t]{12}{*}{$\mathrm{Ni}$} & 10 & $\mathrm{~W}$ & 90 & 20 & 5.90 & 1.48 \\
\hline & & & & 30 & 5.90 & 1.49 \\
\hline & & & & 60 & 5.90 & 1.56 \\
\hline & 15 & & 85 & 20 & 6.22 & 1.51 \\
\hline & & & & 30 & 6.22 & 1.53 \\
\hline & & & & 60 & 6.22 & 1.62 \\
\hline & 85 & & 15 & 20 & 9.21 & 1.84 \\
\hline & & & & 30 & 9.21 & 1.90 \\
\hline & & & & 60 & 9.21 & 2.19 \\
\hline & 90 & & 10 & 20 & 9.38 & 1.86 \\
\hline & & & & 30 & 9.38 & 1.92 \\
\hline & & & & 60 & 9.38 & 2.22 \\
\hline \multirow[t]{12}{*}{$\mathrm{W}$} & 10 & $\mathrm{Ni}$ & 90 & 20 & 5.90 & 0.99 \\
\hline & & & & 30 & 5.90 & 1.00 \\
\hline & & & & 60 & 5.90 & 1.07 \\
\hline & 15 & & 85 & 20 & 6.22 & 1.03 \\
\hline & & & & 30 & 6.22 & 1.04 \\
\hline & & & & 60 & 6.22 & 1.13 \\
\hline & 85 & & 15 & 20 & 9.21 & 1.36 \\
\hline & & & & 30 & 9.21 & 1.42 \\
\hline & & & & 60 & 9.21 & 1.70 \\
\hline & 90 & & 10 & 20 & 9.38 & 1.38 \\
\hline & & & & 30 & 9.38 & 1.44 \\
\hline & & & & 60 & 9.38 & 1.73 \\
\hline
\end{tabular}


we can verify the simulation result of Surface Evolver.

Calculations with W-Ni focused on determining whether Surface Evolver would predict liquid inside solid for any of the configurations. Based on the model given by Eq. [11], the higher surface energy of nickel favors liquid pools at small liquid contents. Table III summarizes several calculations ranging from 10 to $90 \mathrm{vol}$ pct of each phase with contact angles of $20 \mathrm{deg}$, $30 \mathrm{deg}$, or $60 \mathrm{deg}$. Close comparison, for example, with 10 vol pet $\mathrm{Ni}$ inside vs 90 vol pet $\mathrm{W}$ inside shows the $1.56 \mathrm{~mJ}$ at $60 \mathrm{deg} \mathrm{Ni}$ inside is lower than the $1.73 \mathrm{~mJ}$ at $60 \mathrm{deg}$ for the $\mathrm{W}$ inside. This outcome indicates that liquid inside is favored. Likewise, for the same contact angle at $15 \mathrm{vol}$ pct $\mathrm{Ni}$, the lower energy is for the liquid inside the solid $(1.62 \mathrm{~mJ}$ vs $1.70 \mathrm{~mJ})$. However, for all other cases, the lowest energy is for liquid outside the solid. At a $30 \mathrm{deg}$ contact angle, the liquid-vapor to solid-liquid surface energy ratio is 1.45 , and by Figure 4, the transition is at $6 \mathrm{vol}$ pet liquid. For a 40 deg contact angle, liquid inside the solid is favored up to $11 \mathrm{vol}$ pct liquid. Thus, both the solution from Eq. [11] and from Surface Evolver agree in predicting that liquid pockets will form with low liquid contents and higher contact angles.

For many cases considered here, the total surface area is not significantly different. This outcome reflects the spherical configuration after LPS for these small clusters. By implication, we would expect any engineering component to attempt to spheroidize given a sufficiently long sintering time, which brings up an interesting dilemma with regard to dimensional precision in sintering. All shapes tend to spheroidize over time, so longtime sintering would seem to be contrary to high precision sintering.

Over the range examined, the final interfacial energy depends on the final geometric arrangement and the contact angle between the phases, but it is not sensitive to the number of grains and grain boundary energy between phases. In LPS W-Cu, the following order of the configurations is formed based on the total interfacial energy: (1) pore surrounded by $\mathrm{Cu}$, (2) W surrounded by $\mathrm{Cu}$, (3) $\mathrm{Cu}$ surrounded by $\mathrm{W}$, and (4) pore surrounded by W. Therefore, we can easily find the pore and $\mathrm{W}$ in $\mathrm{Cu}$ but not the $\mathrm{Cu}$ and pore in $\mathrm{W}$.

\section{CONCLUSIONS}

Analytic expressions for surface configurations are used to show that liquid pockets inside solid grains are stable in certain situations. Surface Evolver is used to evaluate W-Cu LPS system for finding the possible configuration in equilibrium state in terms of total interfacial energy. The calculations support the analytical expressions for when liquid pools might form inside solid grains, as observed in some LPS products. The combinations of $\mathrm{Cu}-\mathrm{W}$, pore- $\mathrm{Cu}$, and pore- $\mathrm{W}$, the number outside grains, the contact angle between $\mathrm{Cu}$ and $\mathrm{W}$, and the grain boundary energy (the contact angle between outside grains) are considered parameters. The Surface Evolver results are in agreement with both the baseline configurations and the analytical calculations. The configurations and the contact angle between $\mathrm{Cu}$ and $\mathrm{W}$ are dominant parameters, but the number of outside grains and grain boundary energy is not. Based on the simulation, some geometries seem stable; a pore and $\mathrm{W}$ inside $\mathrm{Cu}$ are possible, but liquid $\mathrm{Cu}$ inside solid $\mathrm{W}$ is not expected.

\section{REFERENCES}

1. K.A. Brakke: Susquehanna University, The Surface Evolver: http://www.susqu.edu/facstaff/b/brakke/evolver/html/evolver.htm\# doc\%20top, 2008.

2. R.M. German, P. Suri, and S.J. Park: J. Mater. Sci., 2009, vol. 44, pp. $1-39$.

3. W. Beere: Acta Metall., 1975, vol. 23, pp. 131-38.

4. P.J. Wray: Acta Metall., 1976, vol. 24, pp. 125-35.

5. C.M. Kipphut, A. Bose, S. Farooq, and R.M. German: Metall. Trans. A, 1988, vol. 19A, pp. 1905-13.

6. Y. Liu, R.G. Iacocca, J.L. Johnson, R.M. German, and S. Kohara: Metall. Mater. Trans. A, 1995, vol. 26A, pp. 2484-86.

7. S.J.L. Kang and P. Azou: Powder Metall., 1985, vol. 28, pp. 90-92.

8. N.M. Hwang, S.J.L. Kang, and D.N. Yoon: Metall. Trans. A, 1986, vol. 17A, pp. 1429-31.

9. D.J. McMahon and O.W. Reen: in Modern Developments in Powder Metallurgy, vol. 8, H.H. Hausner and W.E. Smith, eds., Metal Powder Industries Federation, Princeton, NJ, 1974, pp. 4160.

10. P. Lindahl, A.E. Rosen, P. Gustafson, U. Rolander, and H.O. Andren: Int. J. Refract. Met. H., 2000, vol. 18, pp. 273-79.

11. R.M. German: Liquid Phase Sintering, Plenum Press, New York, NY, 1985.

12. W.J. Huppmann and R. Riegger: Acta Metall., 1975, vol. 23, pp. $965-71$.

13. J.L. Johnson, J.J. Brezovsky, and R.M. German: Metall. Mater. Trans. A, 2005, vol. 36A, pp. 2807-14.

14. J. Barta: Powder Metall., 1970, vol. 2, pp. 52-57.

15. R.M. German and S.J. Park: Handbook of Mathematical Relations in Particulate Materials Processing: Ceramics, Powder Metals, Cermets, Carbides, Hard Materials, and Minerals, Wiley, Hoboken, NJ, 2008.

16. J.L. Johnson, L.G. Campbell, S.J. Park, and R.M. German: Metall. Mater. Trans. A, 2009, vol. 40A, pp. 426-37.

17. V.K. Kumikov and K.B. Khokonov: J. Appl. Phys., 1983, vol. 54, pp. $1346-50$.

18. F. Wakai and F. Aldinger: Acta Mater., 2003, vol. 51, pp. 641-52. 